\title{
Genetic Exchanges in the Macrocysts of Dictyostelium discoideum
}

\author{
By M. A. WALLACE* AND K. B. RAPER \\ Departments of Bacteriology and Botany, University of Wisconsin, \\ Madison, Wisconsin 53706, U.S.A.
}

(Received 2 January 1979)

Crosses were made between strains of Dictyostelium discoideum involving two drug resistance markers and the mating-type locus. Over 6000 progeny from 263 individual germinated macrocysts from four single-factor crosses, five two-factor crosses and one three-factor cross were characterized. In most cases the progeny from a single macrocyst were of one genotype, although in the population of macrocysts from any two-factor cross all possible parental and recombinant genotypes were recovered. There was no evidence of linkage between any of the markers examined. No selection against progeny carrying the methanol or the cycloheximide resistance markers was found in two-factor crosses, but selection against progeny carrying both resistance markers was found in the three-factor cross. Germination of macrocysts in all crosses was poor, only once exceeding $2.5 \%$ of the total macrocyst population. A variety of crosses and back-crosses with different parental strains indicated that germination might be influenced by both extrinsic (environmental) and multiple genetic factors. About $10 \%$ of the macrocysts yielded progeny spores that were ambivalent in their mating reactions. After extensive recloning these populations could be resolved to the normal matA (formerly A1) and mata (formerly A2) mating-types and might therefore have represented aneuploids. The results obtained with $D$. discoideum macrocysts differ from those obtained with other cellular slime moulds Dictyostelium mucoroides, Dictyostelium giganteum and Polysphondylium pallidum - and are reminiscent of the results reported for germinated zygospores of Phycomyces blakesleeanus.

\section{INTRODUCTION}

Dictyostelium discoideum Raper (1935) has been shown to produce macrocysts heterothallically (Clark et al., 1973; Erdos et al., 1973b). Two mating-types, originally designated $\mathrm{A} 1$ and $\mathrm{A} 2$, predominate among different natural isolates which when paired can produce macrocysts. One self-compatible (homothallic) strain, AC-4, is known (Cavender \& Raper, 1968). Some strains will mate with either A1 or A2 type myxamoebae, but are by themselves unable to make macrocysts, and thus possibly represent a third mating-type. Following the suggestion of Dr Keith Williams, we will designate the mating-type loci as matA and mata for $\mathrm{A} 1$ and $\mathrm{A} 2$, respectively.

Studies on macrocysts of various species related to, and including, D. discoideum showed that light, temperature and humidity all affected the production and maturation of homothallic macrocysts (Blaskovics \& Raper, 1957; Hirschy \& Raper, 1964; Wienkauff \& Filosa, 1965; Nickerson \& Raper, $1973 a$; Erdos et al., 1976). In addition, macrocyst production by the various strains was obviously mediated by genetic elements other than mating-type (Blaskovics \& Raper, 1957; Erdos et al., 1973b). These factors plus macrocyst

* Present address: Division of Biology and Medicine, Brown University, Providence, Rhode Island 02912, U.S.A. 
age were found to affect germination (Nickerson \& Raper, 1973b). Ultrastructural studies of Dictyostelium mucoroides (Filosa \& Dengler, 1972; Erdos et al., 1973a) and Polysphondylium violaceum (Erdos et al., 1972) have indicated the following basic events to be part of the macrocyst development cycle: (i) aggregation of myxamoebae and primary wall formation; (ii) ingestion of all myxamoebae within the primary wall by an enlarging cytophagic cell; (iii) progression of the cytophagic cell through a binucleate to a uninucleate to a multinucleate state; (iv) cleavage of the cytophagic cell protoplast into many uninucleate progeny myxamoebae; and (v) release of the newly formed myxamoebae from the cyst to reinitiate the life cycle. Thus, genetic material in the progeny myxamoebae is thought to derive only from the nucleus of the cytophagic cell which participated in macrocyst production. Myxamoebae from paired mating-types of heterothallic strains of $D$. discoideum produce macrocysts in a rather similar fashion, but with the formation of the cytophagic cell as the initial event. The finding of a putative synaptonemal complex during the uninucleate stage of the cytophagic cell's development in $P$. violaceum (Erdos et al., 1972) was the first suggestion that macrocysts were sexual structures, while the later discoveries of heterothallism were further indications that macrocysts played roles in genetic exchanges.

Recombination among various types of markers has been reported in the progeny from germinated macrocysts of D. mucoroides (MacInnes \& Francis, 1974), D. giganteum (Erdos et al., 1975) and Polysphondylium pallidum (Francis, 1975). In all of these studies, arguments are presented favouring a meiotic rather than a parasexual mechanism as operative in macrocysts. However, in none of the cases has a simple interpretation been possible. The quantitative data do not fit the expectations of a simple meiotic mechanism, without making further assumptions such as the occurrence of multiple meioses, loss of some meiotic nuclei or differential selection of genotypes in the progeny.

Of all cellular slime moulds, $D$. discoideum is the most studied and best characterized biochemically and genetically. The species is haploid with seven chromosomes. Diploids that arise through rare cell fusions followed by karyogamy can be selected and cultivated. Reselection of haploid segregants from the diploid populations has also proved possible and parasexual and complementation analyses have been performed successfully (e.g. Katz \& Sussman, 1972; Williams et al., 1974; Rothman \& Alexander, 1975; Free et al., 1976; Coukell \& Roxby, 1977).

The purpose of the present study was to observe reassortment patterns in progeny from the germinated macrocysts of $D$. discoideum, with special emphasis on what occurred in individual cysts. The demonstration of genetic exchanges was accomplished. Attempts to germinate macrocysts from crosses of strains carrying known linked genes were unsuccessful. Thus, these studies, centred upon strains WS-10 (matA) and WS-582 (mata), were of necessity restricted to markers with unknown linkage relationships.

\section{METHODS}

Strains. The strains of Dictyostelium discoideum used are listed in Table 1; those with WS numbers are natural isolates, while others are segregants from crosses reported here. Wild-type $D$. discoideum has elliptical spores measuring about $8 \cdot 0 \times 3 \cdot 2 \mu \mathrm{m}$, and spore volume as reflected by mean spore length has been shown to be a useful monitor of ploidy for this species (Sackin \& Ashworth, 1969). All mean spore length measurements for parental and progeny strains used in this study ranged from $7 \cdot 0$ to $8 \cdot 1 \mu \mathrm{m}$, and in no case varied by more than $\pm 0.5 \mu \mathrm{m}$. Mutants resistant to $2 \%(\mathrm{v} / \mathrm{v})$ methanol and to $250 \mu \mathrm{g}$ cycloheximide $\mathrm{ml}^{-1}$ were isolated from the parent strains WS-10 and WS-582, respectively, by Dr G. W. Erdos using $N$-methyl- $N^{\prime}$-nitro- $N$-nitrosoguanidine for mutagenesis according to the procedures of Weber \& Raper (1971) in which the populations were killed to $30 \%$ survival. None of the strains used in this study could grow axenically and all were propagated in association with Escherichia coli $\mathrm{B} / \mathrm{r}$.

The cycloheximide-resistant and methanol-resistant mutants used here are not known to be allelic with imilar mutants isolated from the common laboratory strains NC-4 and V-12. It is unlikely, though, that 


\section{Table 1. Strains of Dictyostelium discoideum}

\begin{tabular}{|c|c|c|c|}
\hline \multirow[b]{2}{*}{ Strain } & \multicolumn{3}{|c|}{ Genotype and allele number* } \\
\hline & mat & $c y c$ & meh \\
\hline WS-7 & $a-1650$ & & \\
\hline WS-10 & $A-1651$ & & \\
\hline WS-70 & $A-1653$ & & \\
\hline WS-195 & $A-1654$ & & \\
\hline WS-205 & $A-1655$ & +-1655 & \\
\hline WS-209 & $a-1656$ & & \\
\hline WS-467 & $A-1658$ & & \\
\hline WS-472 & $A-1659$ & & \\
\hline WS-582 & $a-1652$ & & \\
\hline HMW-100 & $A-1651$ & +-1651 & -1651 \\
\hline HMW-101 & $a-1652$ & -1652 & \\
\hline HMW-102 & $A-1655$ & -1652 & \\
\hline HMW-103 & $A-1651$ & +-1651 & \\
\hline HMW-104 & $a-1652$ & & \\
\hline HMW-105 & $A-1651$ & +-1651 & \\
\hline HMW-106 & $a-1652$ & -1652 & +-1657 \\
\hline HMW-107 & $A-1651$ & -1652 & \\
\hline HMW-108 & $a-1652$ & +-1651 & +-1652 \\
\hline HMW-109 & $A-1651$ & & -1651 \\
\hline HMW-110 & $a-1652$ & & +-1652 \\
\hline HMW-111 & $A-1651$ & & +-1652 \\
\hline HMW-112 & $a-1652$ & & -1651 \\
\hline HMW-113 & $A-1651$ & & \\
\hline HMW-114 & $a-1652$ & & \\
\hline AC-4 & Homot & & \\
\hline
\end{tabular}

* mat, Mating-type; cyc, resistant to $250 \mu \mathrm{g}$ cycloheximide $\mathrm{ml}^{-1}$; meh, resistant to $2 \%$ (v/v) methanol; t-allele number, indicates wild-type from a particular natural isolate.

more than a single locus controls either cycloheximide or methanol resistance in $D$. discoideum (Katz \& Sussman, 1972; Williams et al., 1974; Rothman \& Alexander, 1975). Cycloheximide-resistant and methanolresistant mutants occurred spontaneously in the parental strains WS-10, WS-582 and WS-205 at frequencies less than $1 \times 10^{-5}$. Back mutations from drug resistance to drug sensitivity were screened for, but were not encountered at frequencies above $1 \times 10^{-2}$. All phenotypes for the various strains reported have been stable throughout many repeated clonings and serial transfers.

Media. Two nutrient media were used routinely. Medium LP contained ( $\mathrm{g} \mathrm{I}^{-1}$ in distilled water): lactose, 1.0 ; peptone, 1.0 ; agar, 15.0. It was used both for the growth of stock cultures and for the production of macrocysts. Medium $\mathrm{LP}_{6}$ contained the same amounts of lactose and peptone, but in addition contained $\mathrm{KH}_{2} \mathrm{PO}_{4}\left(2.05 \mathrm{~g} \mathrm{l}^{-1}\right)$ and $\mathrm{Na}_{2} \mathrm{HPO}_{4}\left(0.32 \mathrm{~g} \mathrm{l}^{-1}\right)$. This medium was used for cloning spores and also in testing for drug resistance. When cloning spores, the $\mathrm{LP}_{6}$ overlay contained only $7 \cdot 5 \mathrm{~g}$ agar $1^{-1}$ and is referred to as 'soft' agar. When testing for drug resistance, the $\mathbf{L P}_{6}$ was supplemented with $250 \mu \mathrm{g}$ cycloheximide $\mathrm{ml}^{-1}$ (Sigma) or $2 \%(\mathrm{v} / \mathrm{v})$ methanol (Mallinckrodt, St Louis, Mo., U.S.A.) as appropriate. The bacteria were grown on agar slants containing $\left(\mathrm{g}^{-1}\right.$ in tap water): tryptone, 5.0; yeast extract, $5 \cdot 0 ;$ glucose, $1 \cdot 0$; $\mathrm{KH}_{2} \mathrm{PO}_{4}, 1 \cdot 0$; agar, $15 \cdot 0$. The $E$. coli $\mathrm{B} / \mathrm{r}$ stock was cloned periodically to maintain purity of the culture.

The salt solution (BS) used for washing macrocysts contained ( $\mathrm{g} \mathrm{1^{-1 }}$ in distilled water): $\mathrm{NaCl}, 0 \cdot 6 ; \mathrm{KCl}$, $0.75 ; \mathrm{CaCl}_{2}, 0.3$ (Bonner, 1947). The SDS solution contained $0.005 \%(\mathrm{w} / \mathrm{v})$ sodium dodecyl sulphate in distilled water, the EDTA solution was $0 \cdot 8 \%(\mathrm{w} / \mathrm{v})$ adjusted to $\mathrm{pH} 7 \cdot 1$, and the Str solution was $250 \mu \mathrm{g}$ dihydrostreptomycin sulphate $\mathrm{ml}^{-1}$ in distilled water. Macrocysts were plated for germination on nonnutrient agar (NS); this was $15.0 \mathrm{~g}$ agar $\mathrm{l}^{-1}$ in distilled water supplemented with $250 \mu \mathrm{g}$ dihydrostreptomycin sulphate $\mathrm{ml}^{-1}$.

Production and germination of macrocysts. Equal numbers of spores of the parent strains were inoculated by pipetting $0.1 \mathrm{ml}$ of a mixed suspension with a total of $10^{5}$ spores $\mathrm{ml}^{-1}$ and $10^{8} \mathrm{E}$. coli bacteria $\mathrm{ml}^{-1}$ on to each LP plate. The plates were then overlaid with $5 \mathrm{ml} \mathrm{BS}$ and incubated in the dark for 28 to $35 \mathrm{~d}$ at $22{ }^{\circ} \mathrm{C}$. The macrocysts formed on three plates were harvested and washed five times by centrifugation in BS, then resuspended in $10 \mathrm{ml}$ SDS solution in $50 \mathrm{ml}$ Erlenmeyer flasks which were shaken for 2 to $3 \mathrm{~h}$ on a rotary shaker at $150 \mathrm{rev} . \mathrm{min}^{-1}$. After this, the cysts were washed by centrifugation in fresh changes of BS, resuspended in $10 \mathrm{ml}$ EDTA solution and again shaken for $2 \mathrm{~h}$. Finally, the macrocysts were washed 
twice in the Str solution and the suspension was plated on NS agar. This procedure rid the macrocysts of any contaminating myxamoebae and spores, while the SDS may, in fact, have acted to spur germination. The cysts were incubated in the light at 21 to $22^{\circ} \mathrm{C}$ for 2 weeks. Macrocysts began to germinate 1 week after washing, and continued to germinate for approximately another week. A germinated cyst could be identified by the ruptured cyst casing from which a small sorocarp might have developed directly, or the emerging myxamoebae might have formed a small pseudoplasmodium, migrated for a short distance and then fruited. Macrocysts produced and plated for germination as described above were counted, and the number of germinated cysts was scored by screening at least 500 macrocysts on each of at least four NS plates.

Cloning and scoring macrocyst progeny. Spores from sorocarps derived from germinated cysts were isolated with a sterile needle under a dissecting microscope. To ensure the presence of only a single sorocarp, the area was examined under a compound microscope before and after the procedure. Spores from the single sorus were then placed in $0.6 \mathrm{ml}$ of a thick $E$. coli suspension in distilled water, the mixture was stirred vigorously, and six $0.1 \mathrm{ml}$ samples of the suspension were each mixed with $2.75 \mathrm{ml}$ of molten $\left(45^{\circ} \mathrm{C}\right)$ soft $\mathrm{LP}_{6}$. The soft agar plus spores plus bacteria was poured evenly over a plate previously prepared with $\mathrm{LP}_{6}$ base agar. The plates (six per macrocyst) were incubated in the light at $22{ }^{\circ} \mathrm{C}$, and clones derived from single spores appeared as plaques in the bacterial lawn after 3 to $5 \mathrm{~d}$. Cells from each plaque were isolated with a sterile tooth-pick and regrown in a small screw-capped vial containing $\mathbf{L P}_{6}$ agar streaked with $E$. coli and incubated in the light at $22^{\circ} \mathrm{C}$. Use of the small vials saved media and incubator space. The vials also significantly helped to reduce contamination during long storage periods when populations were repeatedly sampled for phenotype tests. Spores from sorocarps which formed in the vials were used to test for the mating-type and drug resistance of each clone. Thus, the procedure came as close as possible to a detailed and quantitative analysis of all the progeny resulting from the germination of single macrocysts.

To test for drug resistance, a few spores from a vial were inoculated on to a test spot of $E$. coli on an $\mathrm{LP}_{6}$ plus drug plate, usually having seven $E$. coli spots and hence seven tests per plate. The spots were scored for growth after $3 \mathrm{~d}$ incubation in the light at $23^{\circ} \mathrm{C}$. Known sensitive and resistant strains were used as controls. To test for mating-type, the spores from a vial were again transferred by tooth-pick to test spots on LP plates containing $E$. coli plus spores of either a mat $A$ or a mata tester strain. Three plates were incubated at $23^{\circ} \mathrm{C}$ in light-tight metal canisters, and were read after $3 \mathrm{~d}$. If a clone possessed the matingtype opposite that of the tester strain, the myxamoebae would form macrocysts. Conversely, if the unknown and the tester strain had the same mating-type, the myxamoebae would form sorocarps. Additionally, the mating reactions of clones were checked against both mat $A$ and mata testers to reveal any anomalous strains which could mate with both mat $A$ and mata, or could no longer mate at all. Recloning and testing the mating reactions of clones with anomalous mating-types (putative aneuploids) was accomplished by similar cloning and testing methods.

\section{RESULTS}

In screening for compatible strains to be used in genetic analyses, WS-10 (mat A matingtype) and WS-582 (mata) were the first strains found to produce macrocysts that would germinate consistently, even at low levels. A cycloheximide-resistant mutant of WS-582 was then crossed to WS-10. When the macrocysts were germinated, mat $A$ cyc $c^{+}$and mata cyc progeny were identified and remated. Progeny of similar genotype were then identified from this $F_{1} \times F_{1}$ cross, and again mated, and so on, until the $F_{3}$ cross, HMW-103 $\times$ HMW101 , was germinated. The progeny from this cross were then analysed in detail and are reported here as cross $\mathrm{H}$ (see Table 3). No increases in percentage germination were found during these crosses. The methanol-resistant mutant HMW-100 was then crossed to HMW-108 derived from cross $\mathrm{H}$. Tester strains for the mating-types, HMW-113 and HMW-114, were generated by repeated matings in attempts to produce more nearly isogenic strains.

Further screening for competent mating pairs was continued, and ultimately strains WS-205 and WS-195 were found to germinate well when paired with any mata carrying strain. Strains WS-205 and WS-195 were then employed for crosses B, C and F (see Table 3). Table 2 shows the results of attempts to germinate macrocysts from different paired heterothallic strains of $D$. discoideum, and the homothallic strain AC-4. Under identical growth and germination conditions, macrocysts formed with some matA strains germinated much more readily than others, irrespective of the origin of the mata allele. 
Table 2. Germination of macrocysts produced by various paired strains of $D$. discoideum

$\begin{array}{ccc}\text { mat } A & \times \begin{array}{c}\text { mata } \\ \text { strain } \\ \text { strain }\end{array} & \begin{array}{c}\text { Germination } \\ (\%)\end{array} \\ \text { WS-467 } & \times \text { WS-7 } & 0 \cdot 08 \\ \text { WS-467 } & \times \text { WS-209 } & 0 \cdot 11 \\ \text { WS-467 } & \times \text { HMW-104 } & 0 \cdot 29 \\ \text { WS-472 } & \times \text { WS-7 } & 0 \cdot 30 \\ \text { WS-472 } & \times \text { WS-209 } & 1 \cdot 20 \\ \text { WS-472 } & \times \text { HMW-104 } & 0 \cdot 68 \\ \text { WS-205 } & \times \text { WS-7 } & 0 \cdot 97 \\ \text { WS-205 } & \times \text { WS-209 } & 2 \cdot 00 \\ \text { WS-205 } & \times \text { HMW-104 } & 2 \cdot 20 \\ \text { WS-195 } & \times \text { WS-7 } & 0 \cdot 13 \\ \text { WS-195 } & \times \text { WS-209 } & 1 \cdot 00 \\ \text { WS-195 } & \times \text { HMW-104 } & 2 \cdot 30 \\ \text { WS-70 } & \times \text { WS-7 } & 0 \cdot 19 \\ \text { WS-70 } & \times \text { WS-209 } & 0 \cdot 10 \\ \text { WS-70 } & \times \text { HMW-104 } & 0 \cdot 24 \\ \text { HMW-113 } \times \text { HMW-114* } & 0 \cdot 01 \\ \text { AC-4 (homothallic) } & 0 \cdot 01\end{array}$

* HMW-113 and HMW-114 were used as tester strains for the mating-type.

Table 3. Germination and progeny recovery from crosses of $D$. discoideum

\begin{tabular}{|c|c|c|c|c|c|c|}
\hline$\overbrace{}^{\text {Cross }}$ & Code & $\begin{array}{c}\text { Germination } \\
(\%)\end{array}$ & $\begin{array}{l}\text { Total } \\
\text { cysts }\end{array}$ & $\begin{array}{c}\text { Range } \\
\text { of progeny } \\
\text { per cyst }\end{array}$ & $\begin{array}{c}\text { Average } \\
\text { progeny per } \\
\text { cyst }\end{array}$ & $\begin{array}{c}\text { Total } \\
\text { progeny }\end{array}$ \\
\hline HMW-113 × HMW-114 & A & 0.01 & 31 & $3-51$ & $18 \cdot 7$ & 579 \\
\hline WS-195 $\times$ HMW-104 & B & $2 \cdot 20$ & 6 & $5-72$ & $30 \cdot 5$ & 183 \\
\hline WS-205 $\times$ HMW-104 & $\mathrm{C}$ & $19 \cdot 00$ & 7 & $12-37$ & $24 \cdot 0$ & 168 \\
\hline HMW-100 $\times$ HMW-108 & $\mathrm{D}$ & 0.01 & 31 & $1-82$ & $18 \cdot 5$ & 574 \\
\hline HMW-111 × HMW-112 & $\mathrm{E}$ & 0.01 & 33 & $1-85$ & $23 \cdot 7$ & 782 \\
\hline WS-205 $\times$ HMW-106 & $\mathrm{F}$ & $2 \cdot 00$ & 12 & $4-56$ & $17 \cdot 9$ & 215 \\
\hline HMW-102 × HMW-108 & $\mathrm{G}$ & $2 \cdot 00$ & 36 & $2-67$ & $22 \cdot 6$ & 815 \\
\hline HMW-103 × HMW-101 & $\mathbf{H}$ & 0.01 & 58 & $1-91$ & $29 \cdot 9$ & 1734 \\
\hline HMW-100 × HMW-106 & $\mathbf{J}$ & 0.01 & 38 & $1-105$ & $31 \cdot 3$ & 1188 \\
\hline HMW-113 × HMW-114 & $A^{\prime}$ & 0.02 & 11 & $1-33$ & $17 \cdot 0$ & 187 \\
\hline Total & & & 263 & $1-105$ & $24 \cdot 4$ & 6425 \\
\hline
\end{tabular}

The genetic crosses which were analysed are listed in Table 3. The percentage germination achieved varied from 0.01 to $19.0 \%$. Between 1 and 105 progeny were recovered from individual macrocysts, and the mean number of progeny recovered from individual cysts was $24 \cdot 4$.

There are two ways to analyse the progeny from each cross. One is to score the total number of progeny in each genotypic class without regard to the cysts from which they came. The other is to score each cyst qualitatively for the types of progeny recovered from it. The former scoring method gives disproportionate representation in the final data to macrocysts with larger 'burst size'. We find the latter method preferable since it normalizes the data in terms of the number of putative meioses. This method is particularly informative where the total number of macrocysts analysed in any cross is small, and where the range of recoverable progeny from the individual cysts is very large.

Data from a typical cross (D) are presented in Table 4. The total number of clones recovered from a macrocyst are scored in the horizontal rows. Most macrocysts yielded 
Table 4. Analysis of progeny from cross $D(\mathrm{HMW}-100 \times \mathrm{HMW}-108)$

\begin{tabular}{|c|c|c|c|c|c|}
\hline $\begin{array}{l}\text { Cyst } \\
\text { no. }\end{array}$ & matA meh & mata meh $^{+}$ & $\mathrm{matA} \mathrm{meh}^{+}$ & mata meh & Other \\
\hline 1 & - & 15 & - & - & - \\
\hline 2 & 19 & - & - & - & 一 \\
\hline 3 & - & 9 & - & - & - \\
\hline 4 & - & 26 & 一 & - & - \\
\hline 5 & - & 一 & - & 14 & - \\
\hline 6 & 一 & - & 12 & 一 & - \\
\hline 7 & 4 & - & - & - & - \\
\hline 8 & 5 & - & 一 & - & - \\
\hline 9 & - & 40 & - & - & - \\
\hline 10 & - & $\ldots$ & - & 17 & - \\
\hline 11 & - & - & - & 25 & - \\
\hline 12 & - & 9 & 一 & 一 & - \\
\hline 13 & 一 & - & - & 8 & ..- \\
\hline 14 & - & 22 & 一 & - & -- \\
\hline 15 & - & - & 一 & 6 & - \\
\hline 16 & - & - & 10 & - & - \\
\hline 17 & 17 & - & - & 一 & - \\
\hline 18 & - & 1 & 一 & 一 & - \\
\hline 19 & - & - & 25 & - & - \\
\hline 20 & 5 & - & 1 & 1 & - \\
\hline 21 & - & 7 & -- & $\ldots$ & - \\
\hline 22 & - & 82 & - & 一 & - \\
\hline 23 & - & 10 & 2 & 11 & 4 \\
\hline 24 & - & 32 & - & - & - \\
\hline 25 & - & 一 & - & 22 & - \\
\hline 26 & - & - & 18 & - & - \\
\hline 27 & 一 & 一 & 一 & 14 & - \\
\hline 28 & 29 & - & 一 & - & - \\
\hline 29 & 18 & 一 & - & $\ldots$ & - \\
\hline 30 & - & - & 21 & - & - \\
\hline 31 & 一 & - & 13 & - & - \\
\hline Total & 97 & 253 & 102 & 118 & 4 \\
\hline $\begin{array}{l}\text { Qualitative } \\
\text { score }\end{array}$ & 7 & 11 & 8 & 9 & 1 \\
\hline
\end{tabular}

only a single class of progeny, while all four possible classes were recovered from the overall population of macrocysts. The four expected genotypic classes were present in equal ratio when the cysts were qualitatively scored as described. A few macrocysts had more than one genotypic class among their progeny, and one cyst had progeny scored as 'other', i.e. progeny with anomalous mating reactions. A variety of such reactions was found among the progeny of these crosses (see below).

When macrocysts yielded progeny of more than one genotype, the genotypes may or may not have been reciprocal, i.e. they were not restricted to parental and non-parental ditype combinations. Further, some macrocysts yielded odd numbers of genotypes among their progeny (tritypes). Non-reciprocal ditype and tritype macrocysts cannot be explained as coming from single meioses alone, and require more complex interpretations. Overall, on the basis of the qualitative scoring, the three markers used behaved as unlinked Mendelian genes. Further, mat $A$ and mata behaved in a manner consistent with the supposition that they are alternative alleles at a single locus.

Table 5 shows a breakdown of the data from all crosses listed in Table 3. Macrocysts are classified here according to the scheme used by Eslava et al. (1975) for classifying zygospores of Phycomyces. Macrocysts which yielded progeny of only one genotype are thus classified as $1 \mathrm{~T}$, and can be either 1Tp when the genotype is parental, or 1Tr when the genotype is recombinant. Macrocysts yielding two progeny classes are similarly called 
Table 5. Types of macrocysts from 10 crosses of $D$. discoideum

\begin{tabular}{|c|c|c|c|c|c|c|c|c|}
\hline \multirow[b]{2}{*}{ Cross* } & \multicolumn{6}{|c|}{ Type of macrocysts $\dagger$} & \multirow{2}{*}{$\begin{array}{l}\text { Anomalous } \\
\text { maters }\end{array}$} & \multirow{2}{*}{$\begin{array}{c}\text { Anomalou } \\
\text { maters } \\
(\%)\end{array}$} \\
\hline & $1 \mathrm{~T}$ & $2 \mathrm{~T}$ & $2 \mathrm{Tm} / 2 \operatorname{Tr}$ & $3 \mathrm{~T}$ & $4 \mathrm{~T}$ & $>4 \mathrm{~T}$ & & \\
\hline A & 27 & 4 & - & - & - & - & 2 & 6.5 \\
\hline B & 5 & 1 & 一 & - & - & - & 0 & 0 \\
\hline C & 7 & 0 & - & - & - & - & 0 & 0 \\
\hline D & 29 & 0 & - & 2 & - & - & 1 & $3 \cdot 2$ \\
\hline $\bar{E}$ & 19 & 2 & $2 / 0$ & $\ldots$ & - & - & 12 & $36 \cdot 4$ \\
\hline$F$ & 12 & 0 & - & $\ldots$ & - & $\ldots$ & 1 & $8 \cdot 3$ \\
\hline G & 34 & 2 & $2 / 0$ & - & - & - & 1 & $2 \cdot 8$ \\
\hline $\mathbf{H}$ & 30 & 15 & $13 / 2$ & 6 & 6 & - & 8 & 13.8 \\
\hline $\mathrm{J}$ & 14 & 14 & $13 / 1$ & $5 \ddagger$ & $3 \ddagger$ & 2 & NS & NS \\
\hline $\mathbf{A}^{\prime}$ & 10 & 1 & - & - & - & - & 0 & 0 \\
\hline
\end{tabular}

NS, Not scored.

* See Table 3 .

$\dagger 1 \mathrm{~T}$, Macrocysts with progeny of one genotype only; $2 \mathrm{~T}$, macrocysts with progeny of two genotypes, with non-reciprocal genotypes $(2 \mathrm{Tm})$ or reciprocal genotypes $(2 \mathrm{Tr}) ; 3 \mathrm{~T}$, macrocysts with progeny of three genotypes; 4T, macrocysts with progeny of four genotypes; $>4 \mathrm{~T}$, macrocysts with progeny of more than four genotypes.

$\ddagger$ Pseudo 3T and 4T.

$2 \mathrm{~T}$, and can be further subclassed as $2 \mathrm{Tr}$ or $2 \mathrm{Tm}$ depending on whether the two genotypes are reciprocal or mixed, respectively. The $2 \mathrm{Tm}$ macrocysts could not have resulted from a simple ditype meiosis. Similarly, macrocysts from two-factor crosses with three or four genotypic classes are labelled $3 \mathrm{~T}$ and $4 \mathrm{~T}$. The $4 \mathrm{~T}$ macrocysts have all possible progeny classes such as could have arisen from a tetratype meiosis, whereas $3 \mathrm{~T}$ macrocysts might represent tetratype meioses where one of the products failed to survive through germination, sorocarp production and spore cloning. On the other hand, the patterns which were found could have been generated by some non-meiotic mechanism, such as haploidization via transient aneuploidy associated with parasexuality. In the three-factor cross, where eight possible genotypes may be produced, but with no more than four types coming from a single meiosis, 3T and 4T macrocysts can be subclassed into 'true' 'pseudo' types, the latter probably resulting from multiple meioses. Where more than four genotypic classes are recovered from a single macrocyst $(>4 \mathrm{~T})$, these progeny obviously could not be the products of a single meiosis. The above macrocyst classification scheme ignores the presence of any anomalous mating-type clones derived from a cyst.

The great preponderance of all macrocysts were 1T (Table 5). However, four other types of cysts $-2 \mathrm{~T}, 3 \mathrm{~T}, 4 \mathrm{~T}$ and $>4 \mathrm{~T}$ - were recovered. Most $2 \mathrm{~T}$ macrocysts were of subclass $2 \mathrm{Tm}$ rather than $2 \mathrm{Tr}$, while all $3 \mathrm{~T}$ and $4 \mathrm{~T}$ macrocysts in the three-factor cross (cross $\mathrm{J}$ ) were 'pseudo' types rather than 'true'. Table 5 also shows the total number of cysts and the percentage of cysts from which anomalously mating clones were recovered.

Regarding the selectivity of the markers used, Table 6 shows the occurrence of alleles in the progeny from the various crosses. The alternative alleles were recovered in equal numbers from unifactorial and bifactorial crosses (total less J). In the three-factor cross, however, the data were skewed, with a preferential recovery of clones which were sensitive to the drugs. Indeed, no progeny of the genotypes matA cyc meh or mata cyc meh were recovered from cross $\mathbf{J}$.

No clearly detectable linkage was found between any of the markers in these crosses. Table 7 shows the number of times pairs of markers in the various crosses were found in parental $(P)$ or recombinant $(R)$ alignments. The expectation is for a $P: R$ ratio of $1: 1$ in the case of non-linkage between any two pairs, and this was found. The markers used here are not known to be identical with those derived from other strains of $D$. discoideum. The results suggest that the mating-type locus is not found on either of the linkage groups 
Table 6. Occurrence of parental alleles in genotypes of progeny from germinated macrocysts of 10 crosses

$\begin{array}{lrrrrrr}\text { Cross* } & \text { matA } & \text { mata } & \text { meh } & \text { meh }^{+} & c y c & c y c^{+} \\ \text {A } & 17 & 16 & - & - & - & - \\ \text { B } & 5 & 2 & - & - & - & - \\ \text { C } & 4 & 3 & - & - & - & - \\ \text { D } & 15 & 20 & 16 & 19 & - & - \\ \text { E } & 18 & 15 & 12 & 21 & - & 6 \\ \text { F } & 5 & 7 & - & - & 22 & 16 \\ \text { G } & 21 & 17 & - & - & 49 & 57 \\ \text { H } & 68 & 38 & - & - & 9 & 70 \\ \text { J } & 44 & 35 & 29 & 50 & - & - \\ \text { A }^{\prime} & 5 & 7 & - & - & 86 & 149 \\ \text { Total } & 202 & 160 & 57 & 90 & 77 & 79 \\ \text { Total less J } & 158 & 125 & 28 & 40 & \end{array}$

* See Table 3.

Table 7. Linkage tests for the markers in two- and three-factor crosses

\begin{tabular}{|c|c|c|c|c|c|c|}
\hline \multirow[b]{2}{*}{ Cross* } & \multicolumn{2}{|c|}{ mat, meh } & \multicolumn{2}{|c|}{ mat, $c y c$} & \multicolumn{2}{|c|}{$c y c$, meh } \\
\hline & P & $\mathbf{R}$ & $\mathrm{P}$ & $\mathrm{R}$ & P & $\mathrm{R}$ \\
\hline D & 18 & 17 & - & - & - & - \\
\hline E & 16 & 17 & - & - & 一 & - \\
\hline $\mathrm{F}$ & 一 & - & 5 & 7 & 一 & - \\
\hline G & $\ldots$ & - & 21 & 17 & - & - \\
\hline H & - & 一 & 55 & 51 & 一 & - \\
\hline $\mathbf{J}$ & 39 & 35 & 49 & 30 & 38 & 41 \\
\hline Total & 73 & 69 & 130 & 105 & 38 & 41 \\
\hline
\end{tabular}

with $c y c$ or meh. The only known cycloheximide resistance and methanol resistance loci are on linkage groups I and II, respectively (see Katz \& Sussman, 1972).

The contribution of apogamic nuclei to the progeny of the macrocysts would show up as an abnormally high recovery of $1 \mathrm{Tp}$ macrocysts. Likewise, any macrocysts which resulted by the selfing of mat $A$ with $m a t A$, or mata with mata myxamoebae during macrocyst production would further contribute to the 1Tp macrocyst class. Table 8 shows that neither selfing nor apogamic nuclei contributed significantly to the progeny; the 1Tp and $1 \mathrm{Tr}$ macrocysts were recovered in equal numbers from two-factor crosses, as expected when the loci involved are unlinked. In the three-factor cross without linkage between any of the markers, one would expect to find $1 \mathrm{Tp}$ and $1 \mathrm{Tr}$ macrocysts in a $1: 3$ ratio (found $4: 10)$.

As mentioned previously, the preponderance of $2 \mathrm{~T}$ cysts from two-factor crosses were mixed $(2 \mathrm{Tm})$ rather than reciprocal $(2 \mathrm{Tr})$. Further, when $2 \mathrm{~T}$ cysts were examined closely, it was found that one genotype usually predominated, although the genotype which was in the majority seemed to have been selected at random. There was no tendency for the genotypes in $2 \mathrm{Tr}$ cysts to be found in equal proportion as might have been expected if they resulted from a single meiosis followed by non-selective mitoses before germination. Thus, a strong selection against putative meiotic nuclei probably takes place within the cysts prior to germination.

Eleven clones with anomalous mating-types from cross $\mathrm{C}$ were examined in detail. They were exhaustively recloned and their mating reactions were recorded. By the third recloning all anomalous clones had resolved into either mat $A$ or mata mating-types. Subclones with 
Table 8. Numbers of parental and recombinant $1 \mathrm{~T}$ macrocysts in selected crosses

\begin{tabular}{|c|c|c|c|c|c|}
\hline \multirow{2}{*}{$\begin{array}{l}\text { Two-factor } \\
\text { cross }\end{array}$} & \multicolumn{2}{|c|}{ Type of macrocysts } & \multirow{2}{*}{$\begin{array}{c}\text { Three-factor } \\
\text { cross }\end{array}$} & \multicolumn{2}{|c|}{ Type of macrocysts } \\
\hline & $\overparen{1 \mathrm{Tp}}$ & $1 \mathrm{Tr}$ & & $1 \mathrm{Tp}$ & $1 \mathrm{Tr}$ \\
\hline $\begin{array}{l}\text { D } \\
\text { E } \\
F \\
G \\
\text { H }\end{array}$ & $\begin{array}{r}16 \\
14 \\
5 \\
17 \\
21\end{array}$ & $\begin{array}{r}13 \\
15 \\
7 \\
17 \\
17\end{array}$ & $\mathbf{J}$ & 4 & 10 \\
\hline Total & 73 & 69 & Total & 4 & 10 \\
\hline
\end{tabular}

mat $A$ or mata could be derived from a single anomalous clone. This finding seems highly suggestive of an aneuploid or diploid condition being the cause of the anomalous reactions. However, no changes were found in the spore length distributions at any stage during the recloning process. Thus, if the anomalous mating-type clones are the result of disomy for the mating-type locus, then such occurrences cannot be followed by looking at mean spore length distributions.

\section{DISCUSSION}

Since most of the putative meiotic nuclei do not survive in single macrocysts, and since there is no strong bias for macrocysts to be $2 \mathrm{Tr}$ rather than $2 \mathrm{Tm}$, it is not possible to establish from the results presented here whether meiosis occurs in the macrocysts of D. discoideum. MacInnes \& Francis (1974) have, perhaps, presented somewhat more convincing qualitative evidence for meiosis in the macrocysts of $D$. mucoroides. In that homothallic species, all single cysts which were $2 \mathrm{~T}$ from two-factor crosses were found to be of the $2 \mathrm{Tr}$ subclass, thus probably coming from single ditype meioses, while the preponderance of $4 \mathrm{~T}$ macrocysts could have resulted from distant linkage between the markers and their respective centromeres. Further, no $3 \mathrm{~T}$ macrocysts were found in any of their crosses.

From heterothallically produced macrocysts of D. giganteum, Erdos et al. (1975) reported that progeny of only a single genotype was recovered from any single cyst, while all possible parental and recombinant genotypes were recovered in the overall population of macrocysts from a cross. Some macrocysts yielded progeny with anomalous and unstable mating-type reactions which could be resolved, after further reclonings, in a manner analogous to the situation in $D$. discoideum.

The results with $D$. discoideum macrocysts could have come from single meioses occurring in each macrocyst followed by random selection and proliferation of one, two, three or all four meiotic nuclei. On the other hand, such results could have come from some as yet unknown parasexual mechanism where efficient diploidization and haploidization occurs within one or two generations. The putative aneuploids among the macrocyst progeny (anomalously mating clones) could have been formed by a parasexual mechanism involving the loss of whole chromosomes, or by non-disjunction occurring during a meiosis involving strains which are not entirely isogenic. In this regard, due to the probable recessiveness of methanol and cycloheximide resistance, aneuploids with both alternative drug resistance alleles (e.g. $c y c^{+} / c y c$ ) would have been scored as sensitive clones and would not have been detected.

In most cases there was no segregation distortion except in the three-factor cross where meh cyc clones resistant to both drugs were not recovered. Such selection against this phenotype has been noted in parasexual crosses by Katz \& Kao (1974) and by Rothman $\&$ Alexander (1975), but no mechanistic explanation for such marker interaction has been presented. Regardless of the mechanism for haploidization, if the genetic exchange 
frequencies found here reflect the natural system, then it is clear that macrocysts represent a decided survival advantage for $D$. discoideum.

For the macrocysts to be a successful genetic tool, the total number of germinated cysts per cross must be raised. This could be done either by increasing the percentage of germinated cysts, or by finding alternative methods to those reported here for handling large numbers of cysts. It should be mentioned that the macrocysts provide the potential to secure diploids made between non-mutant strains, and to allow the out-crossing of mutants into common wild-type backgrounds. Attempts at genetic studies with the macrocysts of $D$. discoideum at this time must take into account the low germination ability of the macrocysts, some probable mitotic selection against certain progeny classes occurring prior to germination, and finally, the possible shunting of certain progeny classes into the stalk rather than the spores of the emergent sorocarps. When higher percentages of germination are achieved, one might hope to forego individual cyst analysis in favour of random spore analysis from a population of germinated macrocysts. It is important to realize, though, that without a large total number of germinated cysts, random spore analysis is not feasible. The burst size of macrocysts is so highly variable that such analyses will be strongly distorted by the largest macrocysts. One can easily see this demonstrated with the data presented in Table 4, where total progeny scores from the cross would have given results different and conflicting from those obtained by analysing the macrocysts qualitatively. This problem would be even more pronounced if any particular progeny genotype had a low cloning efficiency or a slow growth rate.

For the geneticist, macrocysts could provide the means to map linked genes more precisely than is generally possible with parasexual techniques if, indeed, high frequency recombination within linkage groups is confirmed. Construction of strains with particular genetic complements might then be achieved more easily with macrocysts than via the parasexual routes.

We wish to thank Dr G. W. Erdos for supplying some of the mutant strains used during this research and Ms Ming Tu Chang for many stimulating discussions. We also thank Drs T. J. Leonard, R. L. Dimond and F. Rothman for critical reading of the manuscript. This work was supported by research grants from the National Institutes of Health, U.S. Public Health Service (R01 AI 04915) and the National Science Foundation (GB-40545).

\section{REFERENCES}

Blaskovics, J. C. \& Raper, K. B. (1957). Encystment stages of Dictyostelium. Biological Bulletin 113, 58-88.

BONNER, J. T. (1947). Evidence for the formation of cell aggregates by chemotaxis in the development of the slime mold Dictyostelium discoideum. Journal of Experimental Zoology 106, 1-26.

Cavender, J. C. \& Raper, K. B. (1968). The occurrence and distribution of Acrasieae in forests of subtropical and tropical America. American Journal of Botany 55, 504-513.

Clark, M. A., Francis, D. \& Eisenberg, R. (1973). Mating-types in cellular slime molds. Biochemical and Biophysical Research Communications 52, 672-678.

Coukell, M. B. \& Roxby, N. M. (1977). Linkage analysis of developmental mutations in aggregation-deficient mutants of Dictyostelium discoideum. Molecular and General Genetics 151, 275-288.

Erdos, G. W., Nickerson, A. M. \& Raper, K. B.
(1972). Fine structure of macrocysts in Polysphondylium violaceum. Cytobiologie 6, 352-366.

Erdos, G. W., Nickerson, A. M. \& Raper, K. B. $(1973 a)$. The fine structure of macrocyst germination in Dictyostelium mucoroides. Developmental Biology 32, 321-330.

Erdos, G. W., Raper, K. B. \& Vogen, L. K. $(1973 b)$. Mating-type and macrocyst formation in Dictyostelium discoideum. Proceedings of the National Academy of Sciences of the United States of America 70, 1828-1830.

Erdos, G. W., Raper, K. B. \& Vogen, L. K. (1975). Sexuality in the cellular slime mold Dictyostelium giganteum. Proceedings of the National Academy of Sciences of the United States of America 72, 970-973.

Erdos, G. W., Raper, K. B. \& Vogen, L. K. (1976). Effects of light and temperature on macrocyst formation in paired mating-types of Dictyostelium discoideum. Journal of Bacteriology 128, 495-497. 
Eslava, A. P., Alvarez, M. 1., Burke, P. V. \& DelbrüCK, M. (1975). Genetic recombination in sexual crosses of Phycomyces. Genetics 80, 445462.

Filosa, M. F. \& Dengler, R. E. (1972). Ultrastructure of macrocyst formation in the cellular slime mold Dictyostelium mucoroides. Developmental Biology 29, 1-16.

Francis, D. (1975). Macrocyst genetics in Polysphondylium pallidum, a cellular slime mould. Journal of General Microbiology 89, 310-318.

Free, S. J., Shimke, R. T. \& Loomis, W. F. (1976). The structural gene for $\alpha$-mannosidase- 1 in Dictyostelium discoideum. Genetics 84, 159-174.

Hirschy, R. A. \& RAPER, K. B. (1964). Light control of macrocyst formation in Dictyostelium. Bacteriological Proceedings, 27.

KATZ, E. R. \& KAO, V. (1974). Evidence for mitotic recombination in the cellular slime mold Dictyostelium discoideum. Proceedings of the National Academy of Sciences of the United States of America 71, 4025-4026.

Katz, E. R. \& Sussman, M. (1972). Parasexual recombination in Dictyostelium discoideum: selection of stable diploid heterozygotes and stable haploid segregants. Proceedings of the National Academy of Sciences of the United States of America 69, 495-498.

MacInNeS, M. \& Francis, D. (1974). Meiosis in Dictyostelium mucoroides. Nature, London 251, 321-323.

Nickerson, A. M. \& Raper, K. B. (1973a). Macro- cysts in the life cycle of the Dictyosteliaceae. I. Formation of the macrocysts. American Journal of Botany 60, 190-197.

Nickerson, A. M. \& RAPER, K. B. (1973b). Macrocysts in the life cycle of the Dictyosteliaceae. II. Germination of the macrocysts. American Journal of Botany 60, 247-254.

RAPER, K. B. (1935). Dictyostelium discoideum, a new species of slime mold from decaying forest leaves. Journal of Agricultural Research 50, 135147.

Rothman, F. \& Alexander, E. (1975). Parasexual analysis of the cellular slime mold, Dictyostelium discoideum A3. Genetics 80, 715-731.

Sackin, M. J. \& Ashworth, J. M. (1969). An analysis of the distribution of volumes amongst spores of the cellular slime mould Dictyostelium discoideum. Journal of General Microbiology 59, 275-284.

Weber, A. T. \& RAPER, K. B. (1971). Induction of fruiting in two aggregateless mutants of Dictyostelium discoideum. Developmental Biology 26, 606-615.

Wienkauff, A. M. \& Filosa, M. (1965). Factors involved in the formation of macrocysts by the cellular slime mold, Dictyostelium mucoroides. Canadian Journal of Microbiology 11, 385-387.

Williams, K. L., Kessin, R. H. \& Newell, P. C. (1974). Parasexual genetics in Dictyostelium discoideum: mitotic analysis of acriflavin resistance and growth in axenic medium. Journal of General Microbiology 84, 59-69. 